\title{
HOW TO COUNT PATENTS AND VALUE \\ INTELLECTUAL PROPERTY: USES \\ OF PATENT RENEWAL AND \\ APPLICATION DATA
}

\author{
Jean O. Lanjouw \\ Ariel Pakes \\ Jonathan Putnam
}

Working Paper 5741

\section{NATIONAL BUREAU OF ECONOMIC RESEARCH 1050 Massachusetts Avenue \\ Cambridge, MA 02138 \\ September 1996}

Pakes thanks the NSF (grant no. SBR-9512106) for support. This paper is part of NBER's research program in Productivity. Any opinions expressed are those of the authors and not those of the National Bureau of Economic Research.

(C) 1996 by Jean O. Lanjouw, Ariel Pakes and Jonathan Putnam. All rights reserved. Short sections of text, not to exceed two paragraphs, may be quoted without explicit permission provided that full credit, including (C) notice, is given to the source. 


\title{
HOW TO COUNT PATENTS AND VALUE \\ INTELLECTUAL PROPERTY: USES \\ OF PATENT RENEWAL AND \\ APPLICATION DATA
}

\begin{abstract}
Patent counts are very imperfect measures of innovative output. This paper discusses how additional data - the number of years a patent is renewed and the number of countries in which protection for the same invention is sought - can be used to improve on counts in studies which require a measure of the extent of innovation. A simple renewal based weighting scheme is proposed which may remove half of the noise in patent counts as a measure of innovative output. The paper also illustrates how these data can be used to estimate the value of the proprietary rights created by the patent laws. The parameters estimated in this analysis can be used to answer a series of questions related to the value of patents. We illustrate with estimates of how the value of patent protection would vary under alternative legal rules and renewal fees, and with estimates of the international flows of returns from the patent system. Recent progress in the development of databases has increased the potential for this type of analysis.
\end{abstract}

Jean O. Lanjouw

Department of Economics

Yale University

37 Hillhouse Avenue

New Haven, CT 06520

and NBER

LANJOUW@ECON.YALE.EDU
Ariel Pakes

Department of Economics

Yale University

37 Hillhouse Avenue

New Haven, CT 06520

and NBER

ariel@econ.yale.edu

Jonathan Putnam

Department of Economics

Yale University

37 Hillhouse Avenue

New Haven, CT 06520 
Draft: July 18, 1996

\section{How to Count Patents and Value Intellectual Property: Uses of Patent Renewal and Application Data}

Jean O. Lanjouw, Ariel Pakes and Jonathan Putnam ${ }^{1}$

Patent counts are very imperfect measures of innovative output. This paper discusses how additional data - the number of years a patent is renewed and the number of countries in which protection for the same invention is sought - can be used to improve on counts in studies which require a measure of the extent of innovation. A simple renewal based weighting scheme is proposed which may remove half of the noise in patent counts as a measure of innovative output. The paper also illustrates how these data can be used to estimate the value of the proprietary rights created by the patent laws. The parameters estimated in this analysis can be used to answer a series of question related to the value of patents. We illustrate with estimates of how the value of patent protection would vary under alternative legal rules and renewal fees, and with estimates of the international flows of returns from the patent system. Recent progress in the development of databases has increased the potential for this type of analysis.

\section{Introduction}

Patent data have been used both as a source of information on the extent of invention and as a source of information on the value of the protection generated by the patent laws. This paper discusses, in turn, how patent renewal and application data can be used to further our understanding of each of these issues.

Among measures of the extent of innovation patents are unique in both the richness of the information they contain and in the breadth of their coverage. Patent documents contain detail on the characteristics of individual innovations (eg. its technological area, or its citations to related innovations) and their inventors (both the inventor per se and the owner or the assignee of the patent) not available elsewhere. Moreover, unlike R\&D expenditure data, which is at best available for a subset of larger firms, patent data is available for all firms and individuals over a very long time period (Sullivan, 1994, for example, uses patent renewal data to study 19th century innovation). These features of patent data make it possible to use them to study the efficacy of policies tailored to particular technological areas or

1 Yale University and the NBER, Yale University and the NBER, and Yale University, respectively. Pakes thanks the NSF (grant no. SBR-9512106) for support. 
specific types of firms, the cross country flows of benefits from the patent system, externalities in the knowledge generation process, and many related phenomena.

The primary impediment to fully exploiting this rich data source in the construction of measures of innovation is that the importance of the innovations protected by individual patents varies widely. As a result, patent counts are very imperfect measures of innovative output. This generates two problems. First, there may be systematic differences in the mean value of the innovations protected by different groups of patents. This makes comparisons of counts a biased measure of differences in the value of the innovations being counted (be it their social or their private value). Second, even among groups with similar mean values, the noise in patent counts makes it difficult to use counts to study the causes and consequences of the variation across groups in the value of innovation.

Recent research has attempted to use additional information from the patent system to refine the patent count measure. Studies using patent renewal data exploit the fact that in most countries patentees must pay periodic renewal fees in order to keep their patents in force. Those using patent application data make use of the fact that the same invention may be patented in many countries (producing a patent 'family'). Provided more valuable inventions generate larger and/or longer-lived patent families, we can use the application and renewal data to attach weights to patents and produce weighted patent count indices which are more precise measures of innovative output than raw patent counts (see below).

The second reason for interest in application and renewal data is a direct reflection of the incentives underlying the application and renewal process. Patents represent the legal right to exclude others from using an innovation. Thus the private value of a patent is determined by the difference in the returns that would accrue to the innovation with and without patent protection. Since it is this value which determines both application and renewal decisions, application and renewal data contain information on the value of the proprietary rights created by the patent laws, that is on the value of patent protection.

Since patent rights are seldom marketed, application and renewal data are one of the few sources of information on the value of patent protection available. These data can be distilled into a useable form by combining them with models of application and renewal behavior. We can then investigate a host of questions related to the value of patent protection: how it varies with legal institutions, which countries 
(or firms, or technology groups) gain disproportionately from the patent laws, and so on. In other words, the renewal and application data can be used to investigate the efficacy and the implications of a major tool of Intellectual Property Rights (IPR) policy. In addition, the parameter estimates derived from these models are informative about various features of the innovative process including the nature of the process by which the market for an innovation opens up, and the extent to which the returns from an innovation become obsolete over time.

The purpose of this paper is to provide a review of what has been learned from application and renewal data to date, and then to consider how such data might be used to further explore important issues surrounding innovation. We begin with a discussion of the alternative frameworks that have been used to map the renewal and application data into estimates of magnitudes of more direct interest (Section II). Some of the empirical results currently available are then used to illustrate the potential usefulness of the renewal cum application data in studies of the value of patented ideas (Section III) and in studies of the value of patent protection (Section IV). An appendix outlines the basic data sources.

\section{The Framework of Patent Renewal and Application Models}

Economist's interest in patent renewal data goes back at least to Nordhaus' thesis (1969). Pakes and Schankerman (1984) stimulated broader interest in renewals by showing how to use these data to uncover characteristics of the value of patent protection. We begin this section by outlining the framework used in the Pakes Schankerman study.

They conditioned on a patent application having been made, and endowed each application with an initial one period return to patent protection, say $\mathbf{r}_{0}$, which was assumed to decay deterministically at an annual rate of $\delta$ thereafter. Patentees must pay an annual renewal fee to keep their patents in force and this fee increases in age. A patent owner seeking to maximize the expected discounted value of the (net) returns to patent protection will renew his patent at age ' $a$ ' if and only if current returns, $r_{0} \exp (-\delta a)$, 
are greater than the current cost of renewal, say $c_{\mathbf{a}}{ }^{2}$ Equivalently the patent will be renewed at age a only if $r_{0}>c_{a} \exp (\delta a)$.

The curve labeled $f\left(r_{0}\right)$ in Figure 1 shows the density of the initial distribution of returns. Thus patents with initial returns to the right of the vertical line labeled $c_{1} \exp (\delta 1)$, or the patents with returns in the lined area, renew at age 1. The patents who drop out at the second renewal are those with initial returns greater than $c_{1} \exp (\delta 1)$ but less than $c_{2} \exp (\delta 2)$, or those with returns in the hatched area in the figure.

Assuming a functional form for the initial distribution of returns, Pakes and Schankerman (1984) show that the parameters of this distribution, together with $\delta$, can be estimated by finding the parameter values that make the drop out proportions predicted by the theory 'as close as possible' to those actually observed in the data. The estimates obtained can be used to characterize the distribution of the value of patent protection and its evolution over time (see below).

Pakes (1986) allows a patentee to be uncertain about the sequence of returns that would be earned were the patent to be kept in force. The move to a stochastic model of returns allows for the fact that inventors often apply for patents at an early stage in the innovative process, a stage at which they are still exploring opportunities for earning returns from the use of the information embodied in the patented ideas. In particular, the benefits of protection may increase as the owner learns about the characteristics of the invention and the market. In this model, because there is a possibility that returns will increase, even if current returns are less than the renewal fee, patentees may find it worthwhile to renew in order to preserve the option of protection in the future (once a patent lapses protection is lost forever). Thus rather than a single decay rate, Pakes (1986) estimates a sequence of age specific conditional distributions of returns (the distribution of returns at age ' $a+1$ ' conditional on returns at age ' $a$ '). This additional detail allows us to obtain a deeper understanding of the nature of the innovative process and therefore of the impacts of various policy options (see below).

${ }^{2}$ In this simple deterministic model if the condition that current returns is greater than current fees is not met in the current period, it will not be met at any age thereafter. This fact delivers the myopic renewal rule given above. In the more complicated models that allow for learning about the value of the patent, the renewal rule is more complicated. See the discussion of stochastic renewal models below. 
Lanjouw (1993) estimates a somewhat different stochastic model than that of Pakes (1986) and applies it to more recent and more disaggregated data. In addition, she uses a behavioral model that allows for the fact that a patentee must be willing to defend his rights against infringers in order for patent protection to be meaningful. Importantly, this merging of renewal data with available institutional detail allows one to evaluate different legal institutions and IPR policy reforms (see below, Section IV).

One troubling aspect of these models is that they rely on assumed functional forms. Although the functional forms used were chosen partly to allow the estimates to match available information, there was not that much prior information to bring to bear on this problem, and, due to computational constraints, little robustness analysis was done.

Partly in response to this problem, Pakes and Simpson (1989) develop estimation and testing techniques that do not rely on strong functional form assumptions. They develop "nonparametric" tests of the hypothesis that the returns to patent protection for one group of patents are higher (in a first order stochastic dominance sense) than those for another group. They also show that, with large enough sample sizes and enough variation in renewal fee schedules, patent renewal data is rich enough to identify the entire sequence of conditional distribution functions. Since in reality there is limited variation in fee schedules, they also show what can be determined from any set of schedules provided the sample is large enough. While the sample sizes they had available were large enough to make the testing procedures quite useful (see below), because of insufficient data they did not attempt to 'nonparametrically' identify the conditional distributions of returns. Were the data sets we describe in the last section of this paper available, we are quite sure we could now make significant progress in both the robustness analysis (where recent advances in computers and in computational tools have been little short of miraculous) and in the nonparametric analysis.

Scherer (1996) notes that one striking finding that emerges from all of these studies is that the patents kept in force until the statutory limit of patent protection are significantly more valuable than other patents (see below). In a directed survey, Scherer and Harhoff plan to interview the owners of German patents which reached the statutory term limit in 1995 to obtain detailed information on their profitability, characteristics, and on the role that patent protection played in helping them to appropriate the returns from innovation. This is a coarse and time intensive way of using the renewal data, but the detail it produces may well prove invaluable to future work. 
The first attempt to integrate application data into the analysis of the value of patent protection is in Putnam (1996). He extends Pakes and Schankerman's (1984) analytic framework (which conditions on application) by incorporating the inventor's prior decisions as to whether to apply for patent protection in each country offering such protection. The returns earned as a result of patents in the different countries are allowed to differ both by patent, and, for a given patent, by the characteristics of the country. However the returns earned in a given country are not allowed to depend on whether the patent is kept in force in a second country. Inventors are assumed to apply for a patent in each country where the expected discounted value of net returns (returns minus application and renewal costs) is positive.

Putnam's (1996) study extends the usefulness of patent data in several ways. First, it shows us how to compute estimates of the distribution of the total (domestic and international) value of patent protection accruing to inventions. Second, it allows us to study the international flow of returns from patent protection (see below). Third, it provides us with an ability to estimate differences in the cost of application as a function of both the country of origin of the patent and the country of application. Fourth, because all relevant information about the family size of an invention is available within a few years of first filing, a patent weighting scheme based on applications data can be more timely than one based solely on renewals. Finally, combining application data and renewal data we can produce a weighting scheme which is more precise than one obtained using renewal data alone (see below).

The models discussed above may be extended in many directions. However, they already provide enough structure to illustrate, in the following sections, how patent renewal and applications data might help in improving measures of both the value of patented innovations and the value of patent protection. We begin with the value of patented innovations.

\section{Weighted Patent Counts as a Measure of Innovation}

As noted above, a measure of the output of the innovative process would help us in analyzing a host of policy and descriptive issues related to the causes and effects of technological change. Simple patent count measures of output have been used extensively (see the review in Griliches, 1990) but because patents protect innovations of widely varying (private or social) value, the patent count measure often runs into difficulties. In particular, if different groups of patents have different mean values, patent 
count comparisons can be misleading.

This is illustrated rather dramatically by Schankerman and Pakes (1986). Previous studies had shown the patent/R\&D ratio declining rapidly over time in most Western countries. This, in turn, had created a concern that we had entered into a period of 'technological exhaustion' in which the potential for further productivity growth was small (see Evenson, 1984, and, for a more recent review, Kortum, 1996). Using the Pakes and Schankerman (1984) model, but allowing the parameters of that model to vary with both the patent cohort (the filing year) and the country, Schankerman and Pakes (1986) compare aggregate patent count indices to their estimated patent value indices for each of the U.K., France, and Germany for the period 1955 to 1975 . Table 1 is taken from their study. On the basis of this table they conclude that "...one cannot draw inferences on changes in the value of cohorts of patents during this period from changes in the quantity of patents, for there have been large (and largely offsetting) changes in the 'quality' (or mean values) of patents...". Of course Schankerman and Pakes (1986) refer to the value of patent protection rather than the underlying value of the patented ideas, but, at least a priori one would think that the two are closely related (see below).

Pakes and Simpson (1989) draw similar conclusions after applying their nonparametric testing procedures to Finnish and Norwegian aggregate patent renewal data. It is notable that the inverse correlation between quantity and quality across cohorts of patents was seen even in Finland where, unlike in the other countries, patent counts increased over time. Schankerman (1991), using data from France disaggregated by technology group for the period 1969-81, also finds that decreases in patent counts were partially offset by increases in the average value of patents in his data. ${ }^{3}$

In addition to changes over time in the mean value of patents, it is also possible to discern differences in their value in other dimensions. In the Norwegian and Finnish data, Pakes and Simpson (1989) find that, conditional on the cohort and nationality of the patentee, patents from different ISIC

\footnotetext{
${ }^{3}$ There are several possible reasons for the average quality of the patents in a cohort to be inversely related to their quantity. The simplest is suggested by the estimates of the shape of the patent value distribution. All of the studies discussed above find that most patents are of very little value. Thus small differences in application costs or renewal fee schedules can cause large changes in the number of patent applied for even if the total value of the inventions that could be patented in a cohort remains fairly constant over time. That is, variations in costs of renewal and application should cause a substantial negative intercohort correlation between average patent values and patent counts.
} 
categories have different value distributions. They derive a rough ordering across industry groups: pharmaceuticals, lumber, wood and paper, and machinery and chemicals, dominate; followed by electronics, fabricated metals, and stone, clay and glass; then heavy industries and finally a 'low-tech' grouping. Conditional on cohort and ISIC categories, they do not find (significant) differences in the value distribution across different patentee nationalities. However, in similar tests on German data performed by Lanjouw (1992), equality is rejected in both nationality and technology dimensions (though there was much stronger evidence of significant differences in the technology dimension).

Even when comparing groups of patents with similar mean values, the large variance in patent values generates a degree of noise in patent count measures which makes them extremely difficult to use in studies of innovation. There are varying estimates of the fraction of the total variance in patent values captured by the patent count measure, and all indications are that the quality of the patent counts measure depends on the type of data. For example, Griliches (1990) estimates that the variance in numbers of patents across firms is just $7 \%$ of the variance in the value of patents across firms. The fraction of the variance in patent values captured by differences in patent counts is likely to be even lower in the within firm across time dimension (see Pakes and Griliches, 1980), but higher when we aggregate up to-interindustry differences in patent counts (see Lach, 1995). No matter the data, however, there is little doubt that the variability in patent values significantly reduces the efficacy of patent counts as a measure of invention.

Indeed one of the longest lasting debates in the history of economic measurement has been whether the noise and the biases in patent count measures can be made small enough to make patent counts useful measures of innovative output in economic studies (see, for example, the papers of Kuznets and Sanders, and the comments of Schmookler, in Nelson, 1962). We reiterate here that these problems with the patent count measures are particularly unfortunate since the best alternative, R\&D expenditure data, is not comprehensively available. Moreover, the R\&D data that is available is not broken down by technology group and contains neither the detail on ownership, nor on relationships to other inventions, found in patent data.

Both renewal and application data can be used to develop a weighted patent count measure which mitigates the problems in the standard patent count measure. The idea is straightforward. Rather than simply counting the number of patents, we partition them into groups (say J of them) by the age at which 
the patent was allowed to lapse (at which the renewal fee was not paid) and/or by the set of countries in which patent applications were filed. We then construct a patent value index, say VI, as

$$
V I=\Sigma_{j-1}^{J} w_{j} N_{j} \text {, }
$$

where $\mathbf{N}_{\mathbf{j}}$ is the number of patents in group ' $\mathrm{j}$ ' and $\mathbf{w}_{\mathrm{j}}$ is the weight associated with that group. To construct this index we need the $\left\{w_{j}\right\}$.

There are a number of alternative ways to determine these weights. One is to regress a measure of the private and/or the social value of innovation on the $\mathbf{N}_{\mathrm{j}}$, and let the data estimate the $\left\{\mathbf{w}_{\mathrm{j}}\right\}$. Profits or firm value are candidates for the dependent variable when we are interested in weights for indices of the private value of innovation, while measures of industry-wide productivity would be more appropriate for measures of social value (see, Griliches, 1979, and, more recently, Jones and Williams, 1996, for a discussion). For attempts to establish the structural links between private and social value we could construct a weighting scheme which measures externalities more directly (see Jaffe, 1986, for an example of spillover measures that could be constructed in this way).

There are econometric problems in using regression techniques to obtain precise estimates of the needed weights." However, there are also reasons to expect that we can overcome them. In particular there is, at least potentially, a wealth of patent data. Further, if we are willing to assume some connection between the value of patent protection and the value of patented ideas, there is substantial prior information on the structure of the weights that ought to be of significant help in estimating them. We discuss this latter possibility in more detail now.

A starting point is to assume that the average value of the ideas embodied in the patents in a particular group is proportional to the value of patent protection in that group. If we then assume that the distribution of the value of patent protection is estimated correctly by our renewal and/or application

\footnotetext{
4 Two come immediately to mind. The first is that the within group error in the patent count measure of patent values will produce an errors in variables problem in estimation. We note that in cases where R\&D data is also available they are a potential instrument. The second is the fact that the $\{\mathrm{Nj}\}$ sequences are likely to be highly correlated across observations (especially in studies where a major source of the variation in the data is across time). This is likely to produce a precision problem similar to the problem we often find in distributed lag estimation. The information on the pattern of the weights available from the estimates of the value of patent protection is likely to be particularly helpful in mitigating this problem.
} 
model, we can obtain the weights needed for equation (1) up to a factor of proportionality from working out the implications of our parameter estimates. As yet there are no results available where both the choice of countries in which to apply for a patent and the subsequent renewal decisions are analyzed simultaneously. Consequently we review estimates of weights for groupings determined by the length of time renewed in particular countries, and for groupings determined by the countries in which a given patent was applied for, separately. ${ }^{5}$

Table 2 summarizes this information. Columns 1, 2 and 3 are taken from Lanjouw (1993) and are calculated for the 1974 cohort of German computer and pharmaceutical patents (the paper estimates for four technology groups based on thirty cohorts of data). Columns 4 and 5 are computed from Pakes (1986) and are based on all patents applied for between 1951 and 1979 in France, and on all patents granted that were applied for between 1952 and 1972 in Germany.

The weights in all but the second column sum to one (we come back to Column 2 below). Lanjouw's estimates imply that the average computer patent lapsing at age four is worth three times as much as one lapsing at age three. All of Lanjouw's estimates show patent weights growing approximately linearly in lapse age until the group of. patents that survive to the maximum age (20 years). The latter group are about $50 \%$ more valuable, on average, than those that survive 19 years. Pakes' estimates show somewhat lower weights for patents allowed to lapse in the early ages, especially the weights based on the French data. Thereafter they grow at a fairly steady rate, again until the group of patents that renew until the statutory limit. These are estimated to be $100 \%$ more valuable then the patents that lapse the year before the statutory limit. Note that all columns imply that, were we to attempt to estimate the weights econometrically, a three or four parameter family would suffice.

Most of the differences between columns are explainable. For example the smaller weights for patents that lapse early on in France might have been expected from the fact that the French data contain all patent applications while the German data contain only those patents that were eventually granted. The differences across columns in the weight given to the patents that renewed until the statutory term

5 A more complete database would allow a two-way classification of patents into countries of application and the age at which the patent was allowed to lapse in each country. Since inventions which patent in more countries are typically renewed longer in each country (Putnam, 1991), weights for a-twoway classification can not be built up from the "marginals" of the two one-way classifications. 
limit is a bit more troubling. Patents which are renewed until the statutory term limit are an "open ended" group. That is, since there never is an observed renewal fee that induces these patents to drop out, there is a sense in which we never have an upper bound to their returns. (See the nonparametric analysis in Pakes and Simpson, 1989.) The model determines the value of these patents from a combination of the fact that the possibility of a patent becoming high valued has an effect on initial renewal decisions, and from functional form assumptions. Thus we might expect this weight to be more model dependent than the others-which is just what we find.

The weights in Columns 1, 3, 4 and 5 apply directly to cohorts of patents which are older than the statutory term limit. If we also want to weight the patents in younger cohorts, cohorts for which we have not yet seen the entire sequence of lapse proportions, we will need weights for combined groups ('truncation weights'). These are based on the mean value of patents which are renewed up through a given age. Column 2 provides an example of the needed figures. Comparing Columns 1 and 2 we see that the average value of all computer patents renewed through age three is just over four times the size of the mean value of those lapsing in age three $(0.017$ versus 0.004$)$. If a cohort were only ten years old, we could assign the weights from Column 1 to inventions whose lapse we actually observed, and the age ten weight of 0.052 from Column 2 to all patents still in force in age ten.

Column 6 presents corresponding estimates from Putnam (1996) for patent families. These show the relative mean value of patent families of different sizes. ${ }^{6}$ For example, the average patent family with applications filed in four countries was worth about one and a half times as much as one with applications in three countries. These weights grow approximately log-linearly, again excepting the weight for 18-country families. These are the largest families in his data, and are estimated to be approximately twice as valuable, on average, as a 17-country family.

We close this section by noting that the complementary data needed to fully exploit better indices of the value of innovation are largely available. For example the concordance in Kortum and Putnam (1995) enables the mapping of patents from the technology classification used by the patent examiners

\footnotetext{
${ }^{6}$ The true estimated values, and therefore the corresponding weights, depend not only on the number of patents in patent families but also on the country composition of the patent applications. We have chosen this aggregation to simplify the presentation.
} 
to a standard industrial classification (both by industry of use and by industry of origin, of the patent) and, therefor, the construction of patent value indices by industry. Together with publicly available census and survey of manufacturing data available for the standard classification of industries, this allows one to study innovation at the industry level of aggregation. Also the ownership information in patent documents allows the matching of our patent value indices to input data by the source of funding (private, government funded, and by agencies within the government funded category), and by the location of the R\&D activity (universities, national research labs, private firms, joint ventures, and so on). This makes it possible to examine the efficacy of different institutional arrangements for the production of innovation. By combining weighted patent value indices with the citation information which is also included in the patent documents (see Trajtenberg, 1991; Jaffe, Henderson, and Trajtenberg, 1993), values could be attached to the spillovers that lie at the heart of many of the public policy issues associated with R\&D policy. Patent documents also indicate the number of International Patent Classification subclasses to which a patent is assigned. With patent value indices it is possible to examine whether this measure of the breadth of an innovation is indeed related to its private or social value (Lerner, 1994).

We now move on to a consideration of the use of the patent renewal and application data in studies of the value of patent protection and IPR policy.

\section{The Value of Patent Protection and IPR Policy}

As discussed in the introduction, the estimation of patent renewal and applications models gives us some of the few pieces of information available on the value of protection itself, as distinct from the value of the underlying innovation. We now consider what has been learned about the distribution of the value of patent protection and its evolution over the lifespan of a group of patents. This evolution generates insights into the nature of the learning and obsolescence process. This section closes with a discussion of how the results from these models can be used to analyze the effects of intellectual property policy reforms.

\section{The Magnitude and Distribution of Value}

Currently, renewal model estimates of patent values are available for Germany, France, the U.K. 
and India at an aggregate level (Schankerman and Pakes, 1986; Pakes, 1986; Sullivan, 1994; Fikkert and Luthria, 1996). For Germany and France they are also available disaggregated by the nationality of the patentee and by the type of technology (Schankerman, 1991; Lanjouw, 1993). Estimating a deterministic model, Schankerman and Pakes find that the average value of a patent from cohort 1970 applied for in France and the U.K. was quite low at 11,250 DM (1975 Deutchmarks). In Germany the average value of a patent granted was about 27,300 DM. (just over a third of the patents applied for in Germany were granted). In all countries the distribution of values was very skewed. One percent of applications in France and the U.K. had values in excess of 112,500 DM, while in Germany one percent of granted patents had values above 193,000 DM. Disaggregated value estimates for the 1975 German cohort are in Table 3 (from Lanjouw, 1993). Consistent with the results noted above, they indicate quite a wide variation across technologies in the average value represented by a single patent (from 17,500 to 49,700 1975 DM) and considerable skew in the distribution of value. Similar results were obtained for France by Schankerman (1991).

Putnam (1996) estimates an applications model to derive the first quantitative measure of the total value of the patent rights obtained on an innovation (in contrast to the value obtained as a result of the protection afforded by the patent laws in a given country). This is particularly interesting because it allows us, for the first time, to measure the flows of the value of patent rights across borders, and therefore to answer the question of the extent to which different countries benefit disproportionately from the existence of the international patent system.

Table 4 presents estimates of the mean value of patents granted and held in each of the top five OECD countries. (Value is again calculated as the present value of annual returns to patent protection, net of application and renewal fees, with renewal decisions made optimally.) The data are restricted to include only inventions for which patent applications were made in more than one country. In 1974 this was about $28 \%$ of all inventions reaching patent offices in the OECD. The selection of only internationally-filed inventions eliminates the lowest valued patents from the analysis. As a result, the figures in Table 4 are not directly comparable to those given above for renewal models (as the latter include inventions protected in a single country).

Column 1 of Table 4 shows the average value of a patent granted in each country. Note that although Germany and Japan have economies of similar size, there is a large disparity between the 
expected value of protection in the two countries. The average internationally-filed patent granted by Japan appears to have been worth less than in other countries (about 164,000 1975 DM, while the corresponding value in Germany is $277,000 \mathrm{DM}$ ). Although some of this could be due to compositional differences (for example, a higher share of chemical and pharmaceutical inventions in Germany), Putnam's results suggest that inventors perceive Japanese patent protection to be worth less, holding the 'quality' of the invention constant, than a German patent.

Column 2 of Table 4 provides the average value of a patent held by citizens of each country. Japan is again an outlier, this time holding patents whose value is much higher, on average, than those held by citizens of other major countries. This feature of Japanese patenting is associated with two factors: (1) a relatively large share of Japanese inventions are filed abroad (particularly given its distance from other countries), and (2) a disproportionately large fraction of their patents are filed in the U.S., a country which, with its large market, grants the most valuable patents (see Column 1).

Table 5 presents a subset of the patent 'trade' results from Putnam (1996). For each of three patent granting countries the table presents the following five columns of data: the numbers of patents granted by the country to citizens of other specified 'source' countries; the percentages these numbers represent of the total patents granted by the country to foreigners; the estimated mean value of the associated patent rights; the total value of the patent rights granted to citizens of the source countries; and the share these represent of the total value of patents granted by the country to foreigners. Each row of the table represents a different source country. Thus, the table is a $3 \times 3$ matrix of 5-column blocks; the $i J^{\text {th }}$ block of the matrix gives information about patents originating in country $i$ and patented in country $j$. Because the model applies only to patents filed internationally, the diagonal blocks of the matrix are omitted.

The table shows, for example, that among inventions whose first filing occurred in 1974, Japanese inventors obtained 5,239 patents in the United States, while U.S. inventors obtained 3,836 patents in Japan. The mean value of a Japanese-origin patent in the U.S. was about 325,000 1975 DM, while that of a U.S.-origin patent in Japan was about 148,000 DM. The total value of patents granted by the U.S. to Japan was estimated to be about 1,703 million DM, while Japan granted about 569 million DM worth of patents to U.S. inventors. Thus the U.S. 'trade deficit' with Japan amounted to over 1,074 million DM in 1974 (which represents almost $90 \%$ of its total deficit with the developed world). Note 
that in contrast to the changes in measures over time which were discussed in Section III, in this case differences in numbers underestimate differences in value.

Recall that one of the main motivations for maintaining an intellectual property rights system is to increase the extent to which inventors can capture the returns to investments in R\&D. The ratio of the total private value of patent protection to R\&D expenditures is one measure of the 'implicit subsidy' created by a patent system. This can be compared to other incentive policies such as R\&D tax breaks or direct government funding of research.

Using a disaggregated model of the returns in France and Germany, respectively, Schankerman (1991) and Lanjouw (1993) find subsidy rates on the order of 10-15\% for most technologies. Similar rates are found for aggregate data by Pakes (1986) and Schankerman and Pakes (1986). Putnam (1996), on the other hand, calculates the ratio of the value of international patent rights held worldwide to total R\&D expenditures for each country. Table 4, Column 3, shows the implicit subsidy rates he finds for five countries. They fall between 14 and 34 percent. Both Germany and the U.K. appear to benefit significantly more than the other countries from patenting abroad; they received an 'implicit subsidy' amounting to about $33 \%$ of their R\&D. The figure for France and Japan was about $20 \%$. The stock of international patent rights held by U.S. inventors, despite being the largest stock worldwide, was just $15 \%$ of the value of U.S. R\&D expenditure.

Estimates derived from the renewal and application models are also informative about specific features of the innovative process, such as the speed of learning, exploitation and obsolescence of innovations. One of the early interests in estimating models of the renewal decision was to obtain a measure of the rate of obsolescence on the private returns to innovations. This rate of obsolescence is needed to weight R\&D investments in the construction of knowledge 'stocks' (analogous to physical capital stocks) in the analysis of the private returns to R\&D investments (see Griliches, 1979, for a detailed explanation). The early deterministic models of renewals with a single depreciation rate find rates considerably higher (on the order of $25 \%$ ) than those typically used in the construction of physical capital stocks.

As noted in Section II, the later, stochastic, renewal models allow for greater variation in the 
pattern of returns over time. In these models returns can actually increase over time as agents learn how to utilize their patents effectively. From aggregate data, Pakes (1986) finds that most learning is over by the fifth age of protection. With disaggregated data and a model which allows for zero returns in the early ages, Lanjouw (1993) obtains a similar result, with the bulk of learning completed after four years and all learning over after seven years. In the learning period, many patentees discover that their patents are worthless, while others learn that substantial returns can be earned from their patents. After this period returns decay more or less at a common rate.

\section{IPR Policy}

The value of the legal right to the exclusive use of an innovation and hence the incentives created by a patent system depend on features of the system which can, and do, vary across countries and time. For example, statutory patent terms range from zero years (excluded products, such as pharmaceuticals, in many countries) to 20 years (EC; soon to be joined by signatories of the GATT treaty). Application and renewal fees have also varied widely--the latter from zero (the U.S. until recently) to over 3,300 DM (for the twentieth year of protection in Germany). Since these variables affect the duration of patents, not only do they help determine the incentives to invest in research, they also affect the social costs of allowing patent monopolies. To date fees and term limits have been set in an ad hoc fashion, usually to cover patent office costs. However, there is potential for these features to be designed so as to create a given level of expected private returns at a lower social cost (for theoretical work on this issue see Nordhaus, 1969, and, more recently, Cornelli and Schankerman, 1996). Estimates from structural renewal or applications models can be used to obtain empirical measures of one side of this tradeoff: how changes in the fee schedule and the statutory term influence the private value of patent rights and hence the incentives to do R\&D.

Enforcement and the costs of enforcement also have a bearing on the benefits of patent protection. The lack of enforcement figures highly in discussions with developing country governments while the high costs of prosecuting infringements is receiving a great deal of attention elsewhere. The U.S. has seen sweeping changes to its IPR law and practice since the early 1980s, including the establishment of a new federal court of appeals to hear patent cases. Renewal data can be used to measure how sensitive 
the returns to patenting are to various changes in the law or legal policy. Lanjouw (1996) embeds an infringement/litigation model into a renewal model to take into account the fact that patentees must be willing to enforce their rights for protection to be meaningful. While in the absence of data related to filed court cases this approach relies heavily on structural assumptions, it provides the only measure to date of the 'hidden' effects of legal policy changes on the number of patents and their duration - effects which are over and above changes in direct legal costs. Moreover legal data is increasingly available and is currently being matched to patent data.

Tables 6 and 7 present simulated estimates of the impacts of specified changes in fees, term lengths and legal policy on the benefits of patent protection (for details on the construction of these estimates, and further simulated policy experiments, see Lanjouw, 1996). Since we have not yet estimated a model which analyzes the application and subsequent renewal decisions jointly, the results in these tables condition on the applications in a particular cohort, and then ask how the returns to protection for those patents change under alternative institutional arrangements ${ }^{7}$. The first column in each table shows the mean and percentiles of the value distribution for the 1975 cohort of German computer patents. These are estimated with the actual parameters of the IPR system in Germany - with legal fees paid by the losing party (the British Rule, BR) and a statutory term limit of 20 years. There were 1,172 German computer patents in 1975. Table 6 shows how patent value and the average revenue collected by the patent office change with the alterations in renewal fee schedule. The reform being considered is indicated in bold type at the top of each column. Included in Column 3 of the table is the simulated effect of switching to a schedule (denoted CS) which may correspond more closely to an optimal design (based on the analysis in Cornelli and Schankerman, 1996).

In Table 7, each of Columns 2 through 7 shows the effect on patent value of legal policy reforms (with the set of policy changes again indicted in bold at the top of the columns). Of particular interest is that both the move from the British Rule to the American Rule (with litigants paying their own legal fees), and the move from a 20 year to a 17 year statutory term limit have cause large changes in the value of patent protection.

${ }^{7}$ I.e. a more complete model would allow the quantity and quality of applications to also vary with the institutional arrangement, but such a model has yet to be estimated. 
There are many directions in which this type of analysis could be developed further. Current theoretical work is making progress in specifying more realistic models of the litigation and settlement process. As our understanding progresses on this front it will be possible to more accurately specify the renewal rule. The analysis can, and should, be tailored to the legal environment of the compacts on untries and the technologies under consideration.

Concurrent with theoretical developments, the databases relevant to this type of analysis are improving in quality and size, and becoming more easily accessible. This because countries are computerizing their patent offices and court systems. The emerging data bases include not only data on patent applications and renewals, but also legal data on the filing and the resolution of litigation suits, and hence will allow us to estimate more complex models. The size of these data sets will also enable us to estimate our models separately for more finely differentiated subclasses of data (for eg. by technology group, firm size, type of inventor, etc.). The data appendix provides an overview of ways of accessing the patent data needed to extend these studies. 


\section{Data Appendix}

Application and renewal data are currently collected and disseminated separately: renewal data are collected by national patent offices, while patent family data are only assembled by private database vendors. The extent and the history of renewal data computerization varies widely by country. Typically, computerization did not begin until the mid-1970s, so complete cohort observations are only now becoming available.' Most countries have a policy of charging for access to these data on a per patent basis, but have typically waived the fee for academic researchers seeking large samples.

The most comprehensive source of computerized legal status data currently available is the Inpadoc Legal Status file. This file does not allow one to link patents from the same family. Inpadoc (formerly the International Patent Documentation Center) is now owned by the European Patent Office (EPO). The EPO continues to market a commercial version of the Inpadoc file through online database services like Orbit-Questel and Dialog. The EPO also markets this file on tape, at a cost of 11,000 DM for the backfile and 11,000 DM per year for monthly updates. (Prices and descriptions are quoted from the Epidos catalog of products and services published by the EPO. Prices are current as of June 1995.) The file contains legal status information for Austria, Belgium, Switzerland, Germany, the former East Germany, European patents, France, the United Kingdom, Hungary, Luxembourg, Monaco, Netherlands, Sweden, the United States, and Patent Cooperation Treaty applications (which are filed in order to establish novelty in all countries designated by the applicant). The commencement of coverage varies by country.

Separately, Inpadoc also produces patent family information covering about 50 countries. The Inpadoc file is available from the EPO at a fee of 90,000 DM for the patent family information and an additional 90,000 DM for the 'bibliographic' information, such as the firm identifier and the IPC

\footnotetext{
${ }^{8}$ It can also vary within a country. For example, computerized archives in Germany contain all patents valid in 1978 or later and all patent applications filed in 1981 or later.

9 The manual collection of older renewal data is often infeasible. These data are recorded in a variety of formats (archive volumes, IBM-style computer cards, microfiche) and with varying degrees of completeness in their complementary data (such as firm identifiers and IPC codes).
} 
classification. These fees are for the current year's data ${ }^{10}$; the cost of the two complete backfiles, which extend from 1968, is a one-time payment of $90,000 \mathrm{DM}$ each. The purchase of part of the files is also possible.

\footnotetext{
${ }^{10}$ It should be recognized that, because a patent family's composition is revealed over a multi-year period (because of a long pendency between application and examination in countries that keep applications secret), purchasing the 'current year' information does not equate to purchasing the 'current cohort,' which will not be revealed for several years. Moreover, because patent examinations may, in some jurisdictions, be delayed at the discretion of the applicant, the final outcome of the application process will not be known, for some inventions, until ten years or more after their filing date. Thus, studies that seek to restrict the sample to granted patents, rather than to applications, must be careful to avoid the problems raised by sample truncation.
} 


\section{References}

Cornelli, Francesca and M. Schankerman (1996) "Optimal Patent Renewals," The Economics of Industry Group Discussion Paper no. EI/13. STICERD. The London School of Economics.

Evenson, Robert (1984) "International Invention: Implications for Technology Market Analysis" in R\&D, Patents and Productivity,-Zvi Griliches (ed.). Chicago: University of Chicago Press.

Fikkert, Brian and Manjula Luthria (1996) "Estimates of the Private Value of Patent Protection in India," Mimeo. University of Maryland.

Griliches, Zvi (1979) "Issues in Assessing the Contribution of Research and Development to Productivity Growth," Bell Journal of Economics. Vol. 10, no. 1 (Spring).

Griliches, Zvi (1990) "Patent Statistics as Economic Indicators: A Survey," Journal of Economic Literature. Vol. XXVIII. pp. 1661-1707.

Jaffe, Adam (1986) "Technological Opportunity and Spillovers of R\&D: Evidence from Firms' Patents, Profits, and Market Value," American Economic Review. Vol. 76, no. 5. pp. 984-1002.

Jaffe, Adam, Rebecca Henderson and Manuel Trajtenberg (1993) "Geographic Localization of Knowledge Spillovers As Evidenced By Patent Citations," Quarterly Journal of Economics. Vol. 108. pp. 577-598.

Jones, C. and J. Williams (1996) "Too Much of a Good Thing? The Economics of Investment In R\&D," Mimeo. Stanford University.

Kortum, Samuel (1996) "Research and Productivity Growth, Theory and Evidence from Patent Data," Mimeo. Boston University.

Kuznets, Simon (1962) "Inventive Activity: Problems of Definition and Measurement," pp. 19-53, in R.R. Nelson (ed.), The Rate and Direction of Inventive Activity. Universities NBER Conference Series No. 13, Princeton University Press.

Lach, Saul (1995) "Patents and Productivity Growth at the Industry Level: A First Look," Economics Letters. Vol. 49, pp. 101-108.

Lanjouw, Jean O. (1996) "Beyond Lawyers' Fees: Measuring the Indirect Effects of U.S. Intellectual Property Reforms," Mimeo. Yale University. 
Lanjouw, Jean O. (1993) "Patent Protection: Of What Value and for How Long?" NBER Working Paper no. 4475.

Lanjouw, Jean O. (1992) The Private Value of Patent Rights: A Dynamic Programming and Game Theoretic Analysis of West German Patent Renewal Data, 1953-1988. Ph.D thesis. London School of Economics.

Lerner, Josh (1994) "Patenting in the Shadow of Competitors," Journal of Law and Economics. Vol. 38, no. 2, pp. 463-96.

Nordhaus, William D. (1969) Invention, Growth, and Welfare: A Theoretical Treatment of Technological Change. Cambridge: M.I.T. Press.

Pakes, Ariel (1986) "Patents as Options: Some Estimates of the Value of Holding European Patent Stocks," Econometrica. Vol. 54. pp. 755-784.

Pakes, Ariel and Zvi Griliches (1980) "Patents and R\&D at the Firm Level: A First Report," Economics Letters, Vol. 5, pp.377-81.

Pakes, Ariel and Mark Schankerman (1984) "The Rate of Obsolescence of Patents, Research Gestation Lags, and the Private Rate of Return to Research Resources," in Zvi Griliches (ed.), R\&D, Patents and Productivity. NBER Conference Series. Chicago: The University of Chicago Press.

Pakes, A. and Margaret Simpson (1989) "Patent Renewal Data," Brookings Papers: Microeconomics. pp. 331-410.

Putnam, Jonathan (1991) "What Can We Really Learn from the (International) Patent System?" Mimeo. Yale University.

Putnam, Jonathan (1996) The Value of International Patent Protection. Ph.D. Thesis. Yale University.

Sanders, Barkav (1962) "Some Difficulties in Measuring Inventive Activity," pp. 53-92, in R.R. Nelson (ed.), The Rate and Direction of Inventive Activity. Universities NBER Conference Series No. 13, Princeton University Press.

Schankerman, Mark (1991) "The Private Value of Patent Rights in France, 1969-87: An Empirical Study of Patent Renewal Data," NBER Working Paper no. 3780, July.

Schankerman, Mark and Ariel Pakes (1986) "Estimates of the Value of Patent Rights in European Countries during the Post-1950 Period," The Economic Journal. Vol. 96. pp. 1052-1076. 
Scherer, M. (1996) "The Size Distribution of Profits from Innovation," Mimeo. Harvard University.

Schmookler, Jacob (1962) "Comment," in R.R. Nelson (ed.), The Rate and Direction of Inventive Activity, Universities NBER Conference Series No. 13, Princeton University Press.

Sullivan, Richard (1994) "Estimates of the Value of Patent Rights in Great Britain and Ireland, 1852-1876," Economica. Vol. 61, pp. 37-58.

Trajtenberg, Manuel (1990) "A Penny for Your Quotes: Patent Citations and the Value of Innovation," The Rand Journal of Economics. Vol. 21, no. 1. 


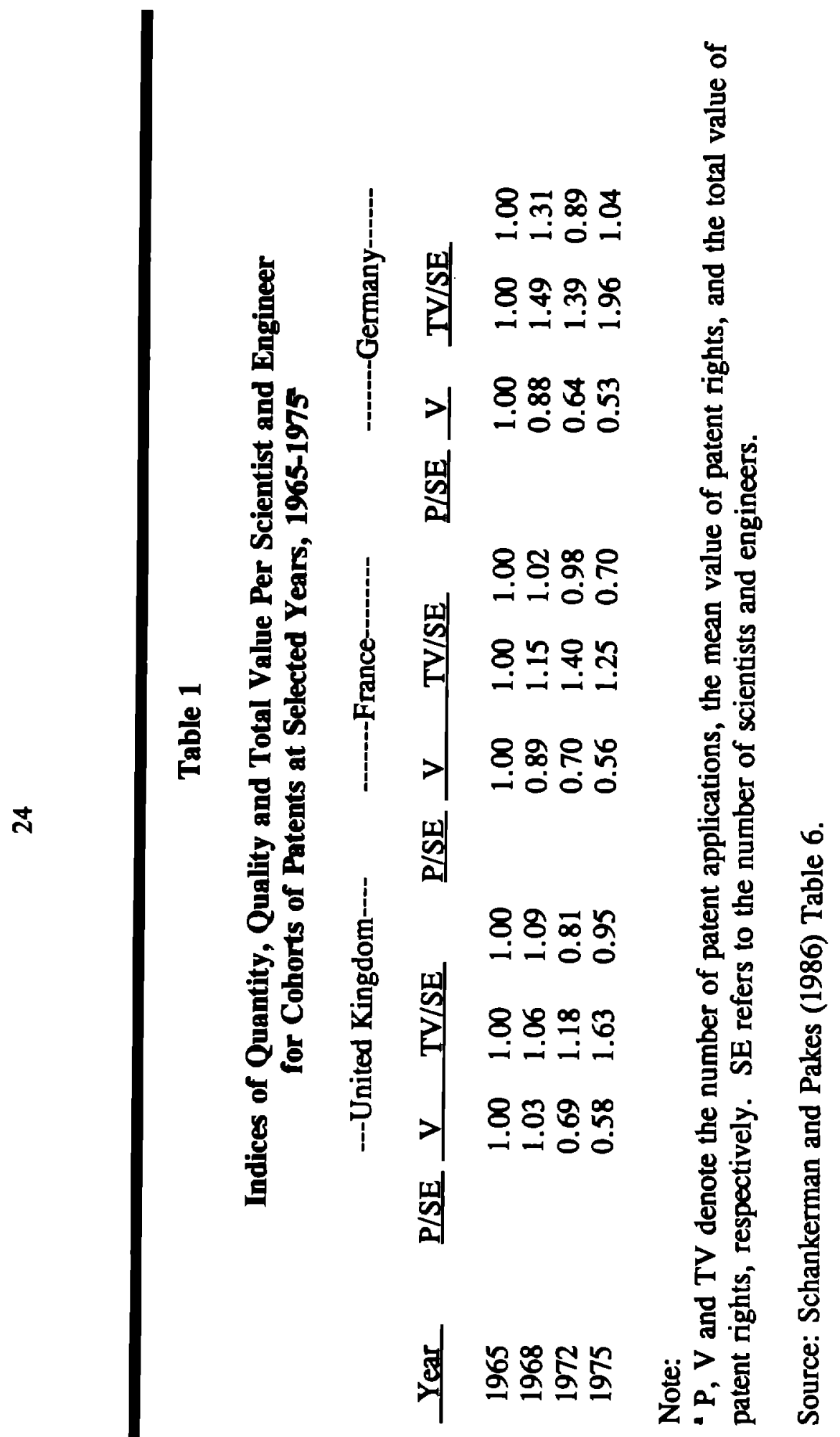




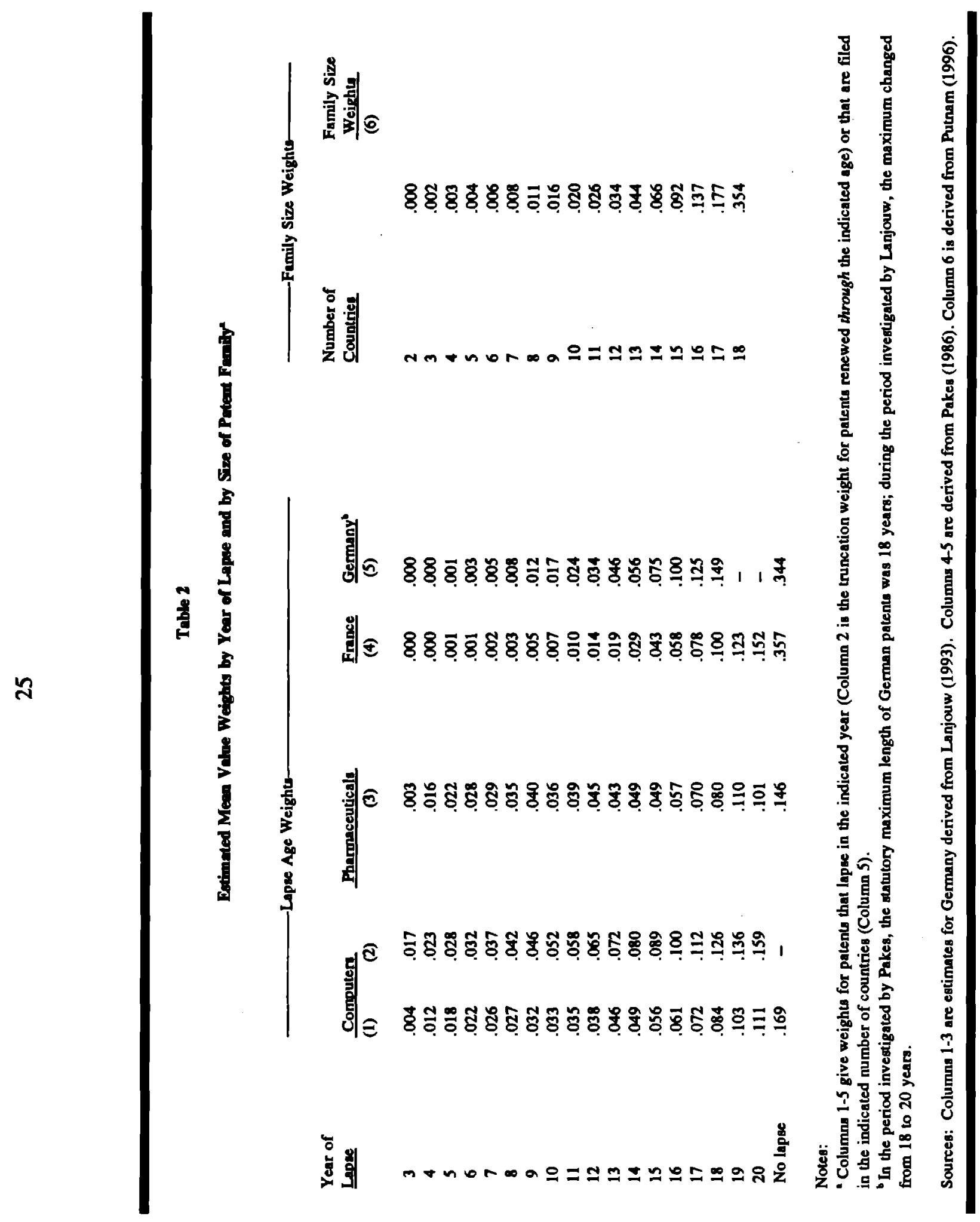




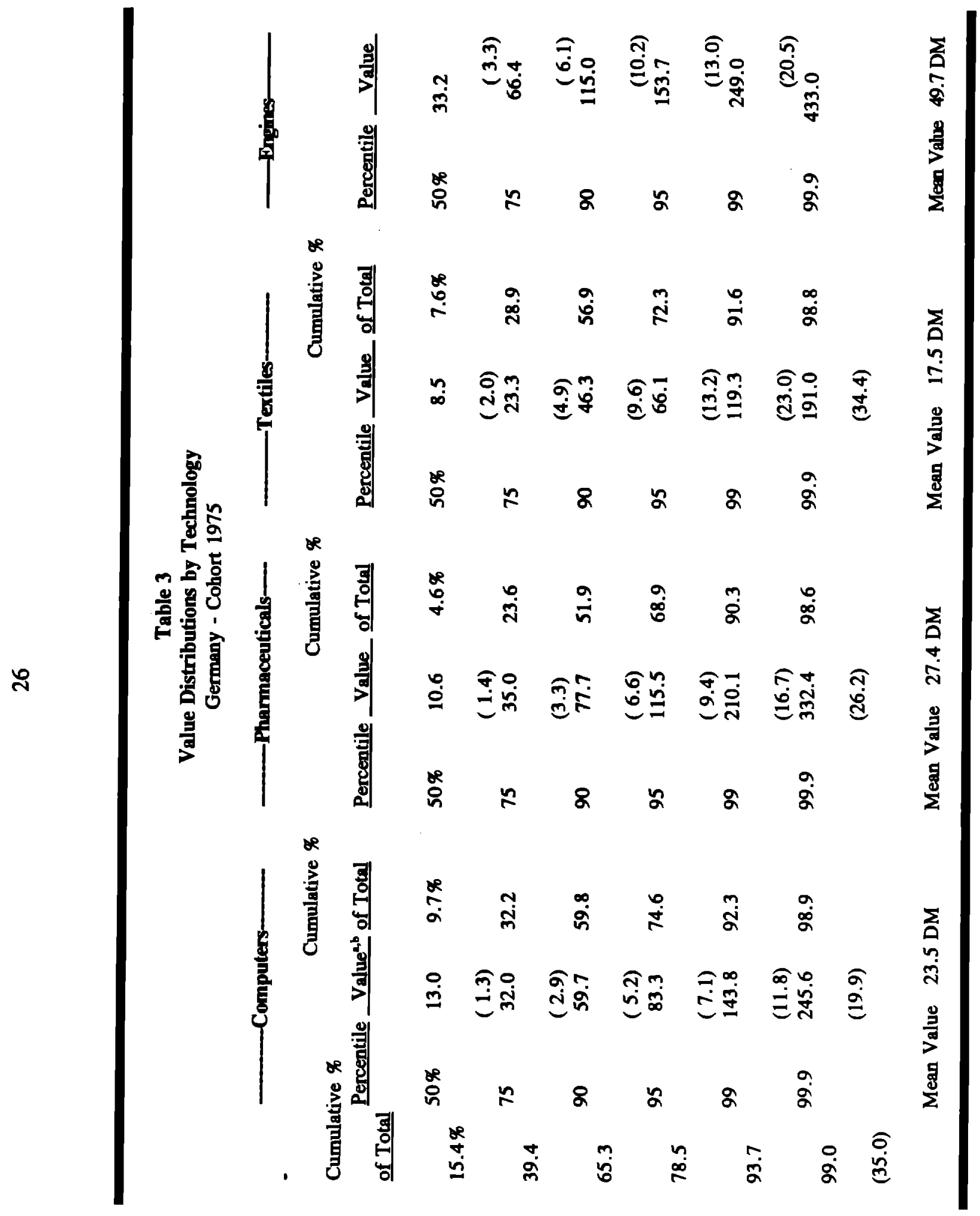




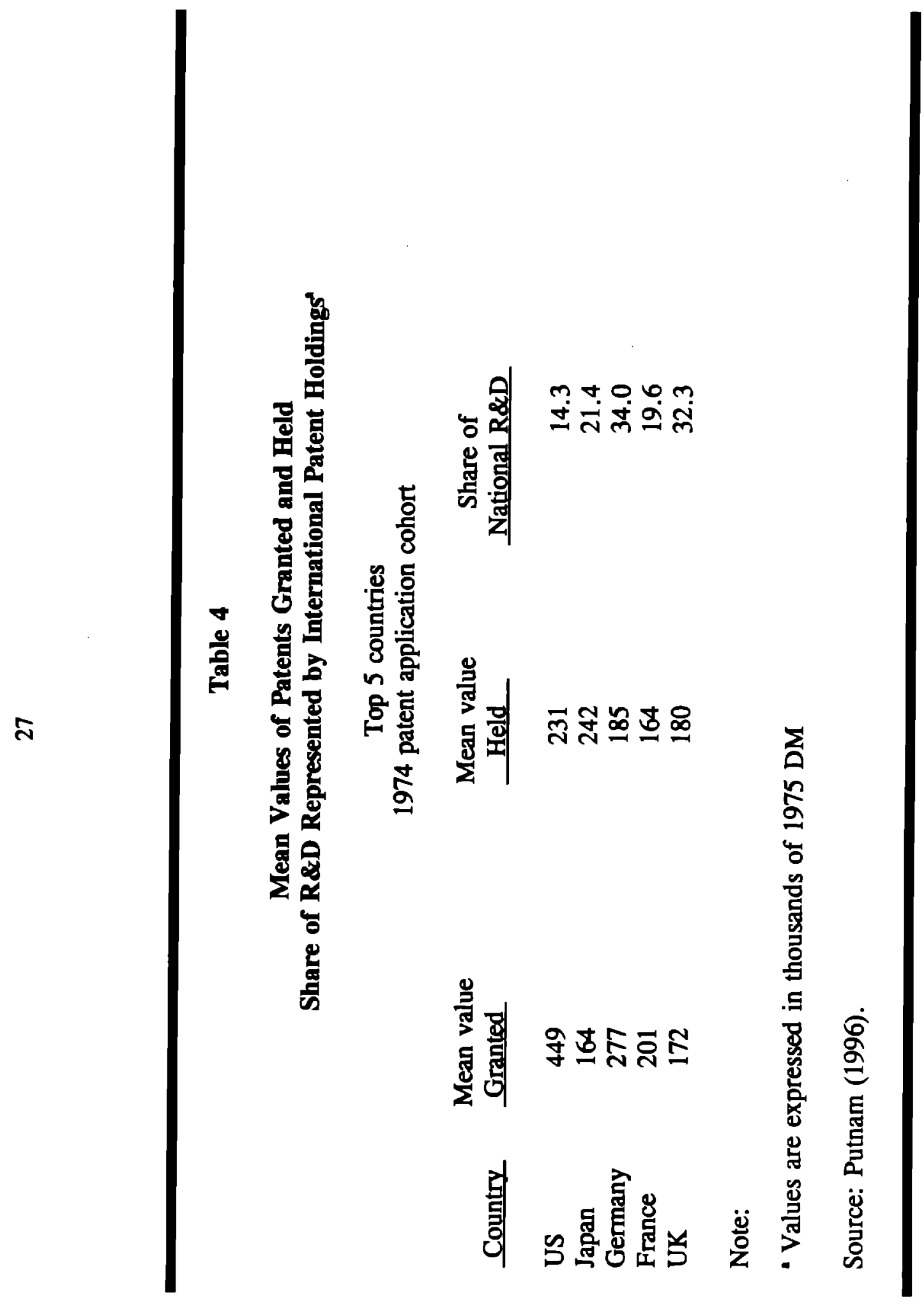




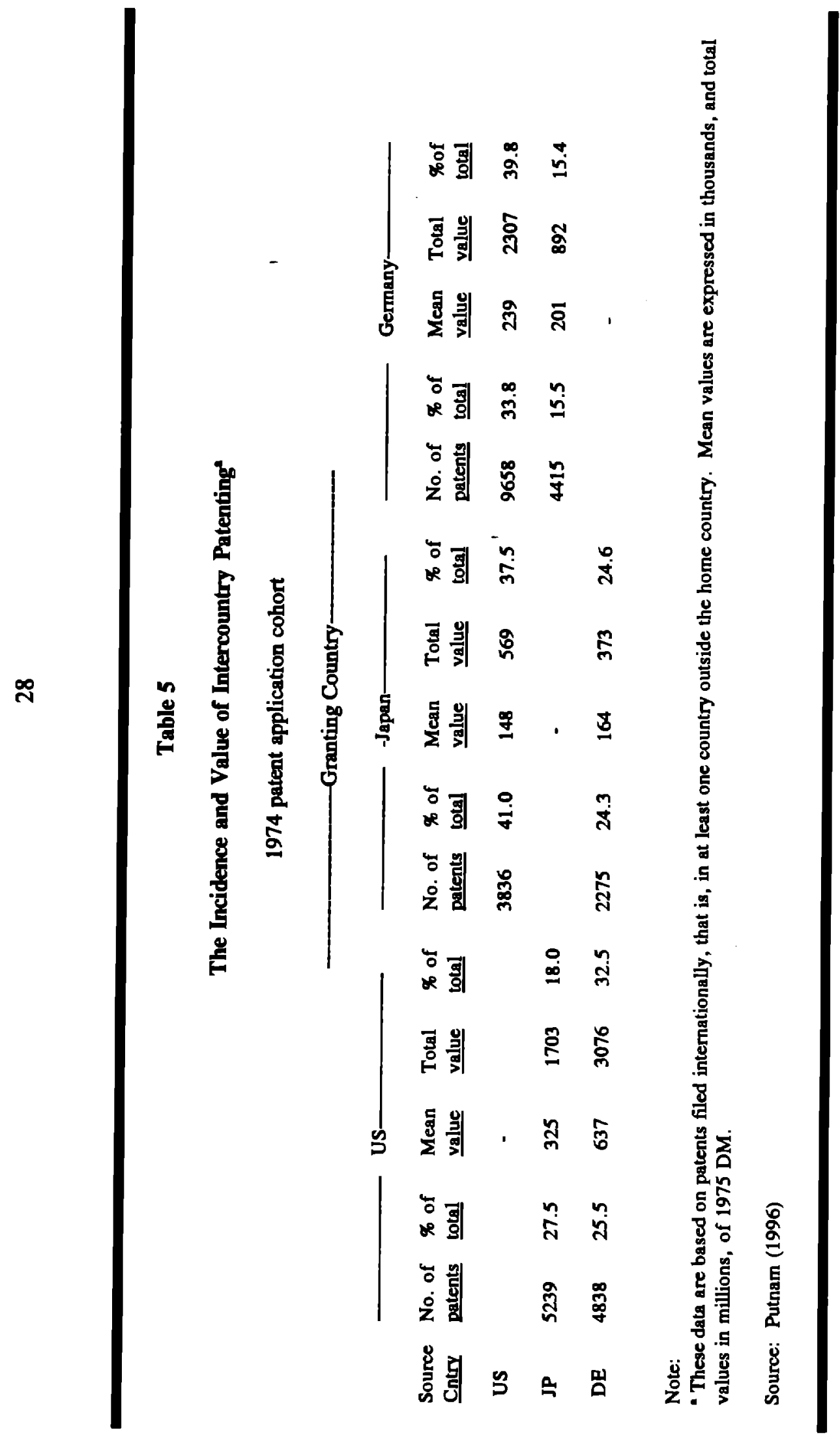




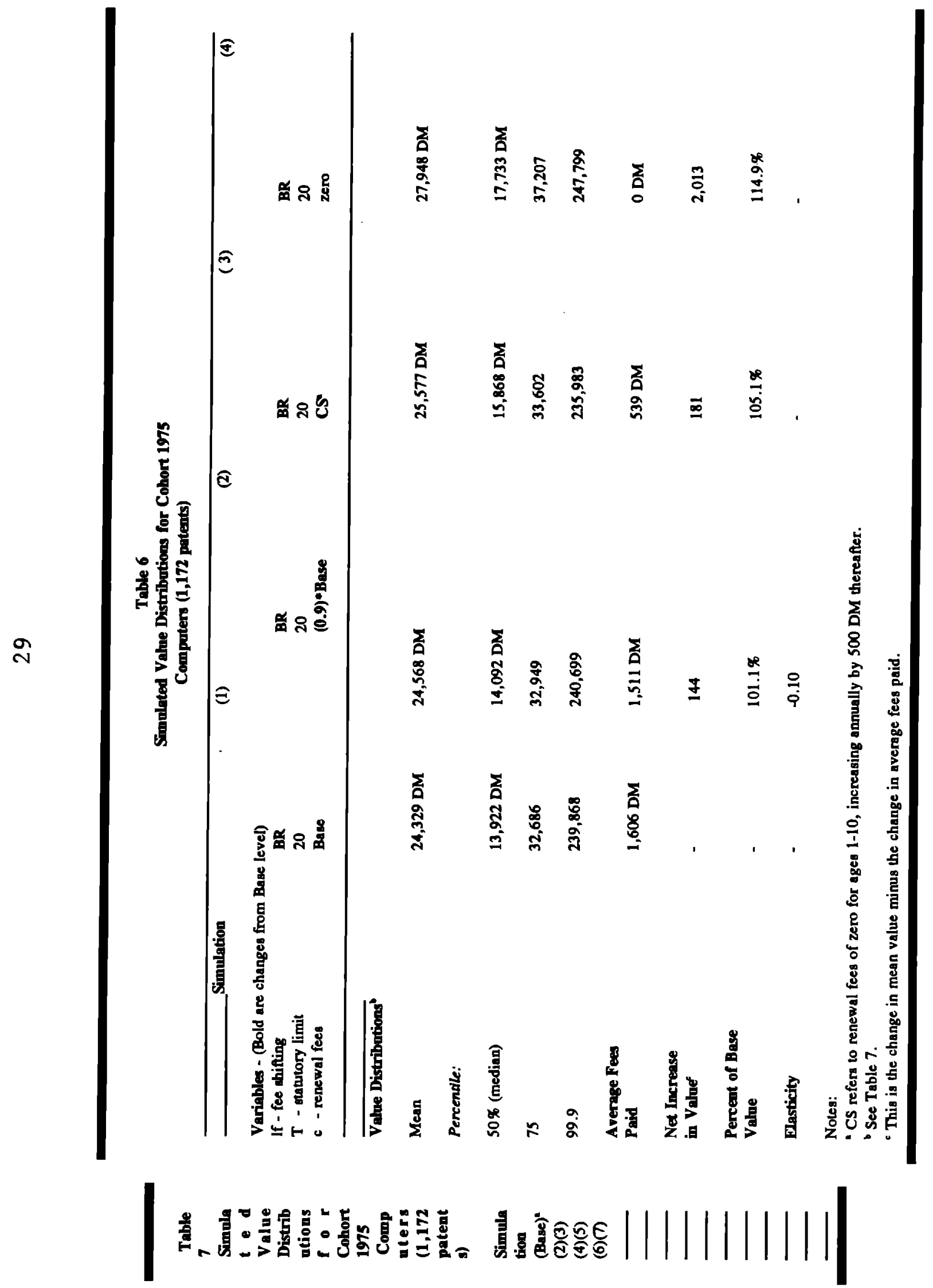




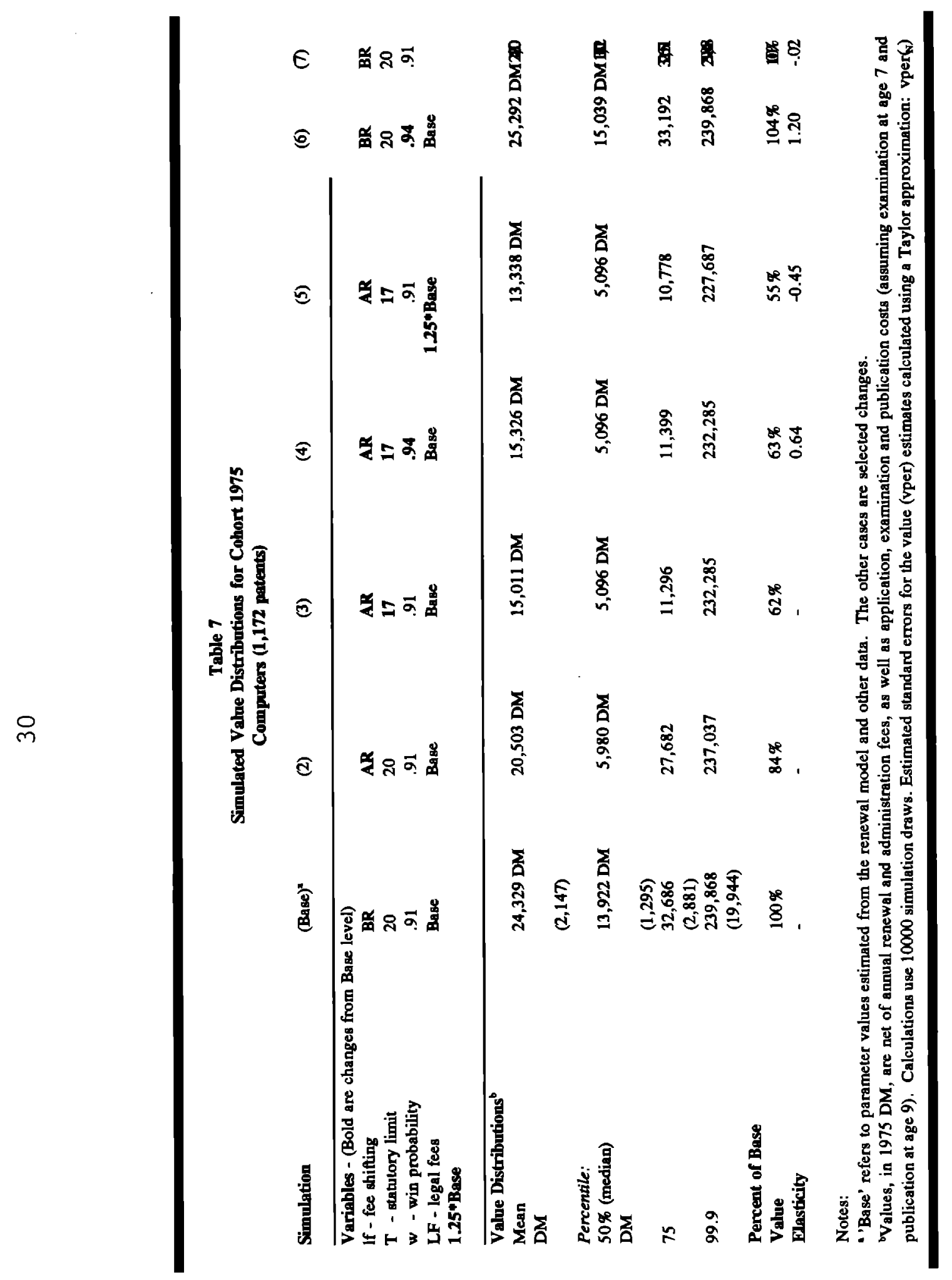




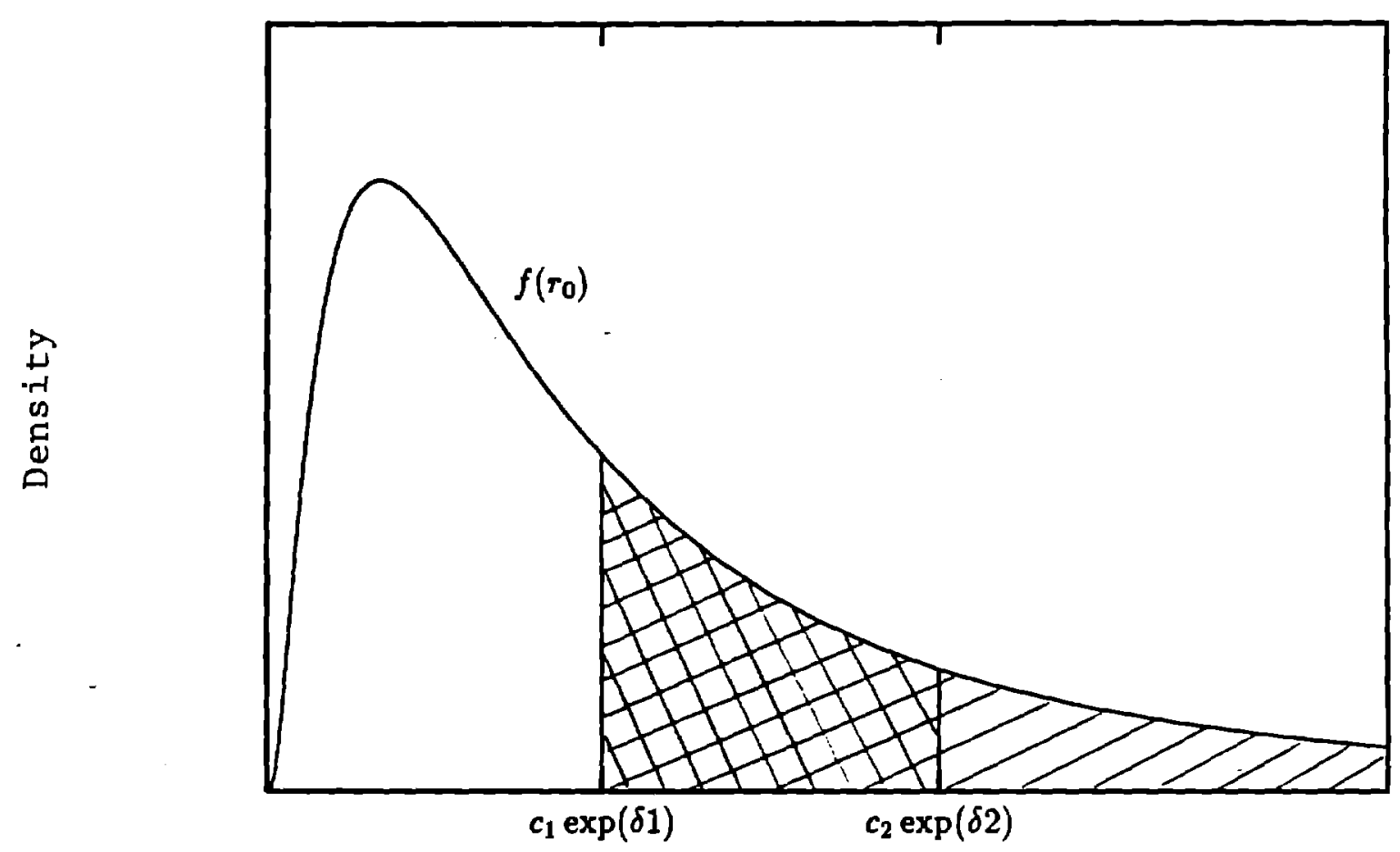

Figure 1: The density of initial returns corresponding to 1 or 2 periods of renewal 